\title{
The Effects of Thinking Style Based Cooperative Learning on Group Creativity
}

\author{
Soon-Hwa Kim ${ }^{1}$, Ki-Sang Song ${ }^{2}$ \\ ${ }^{1}$ Department of Computer Education for the Gifted, Korea National University of Education, Chung-won, Korea \\ ${ }^{2}$ Department of Computer Education, Korea National University of Education, Chung-won, Korea \\ Email: soona6570@gmail.com, kssong@knue.ac.kr \\ Received 2012
}

\begin{abstract}
Recent studies have emphasized group creativity within a socio-cultural context rather than at an individual level, but not many researchers reported strategies for developing group creativity. This paper aims to explore strategies to enhance group creativity based on the theoretical basis of thinking styles by Sternberg. The hypothesis was that groups with members of diverse thinking styles would show greater gains in creative performance. In this study, the participants $(n=72)$ were divided into 24 three-person groups. Each group was given the task to create a game using Scratch programming language. Among the 24 groups, eleven groups $(n=33)$ consisted of heterogeneous thinking styles, and the other thirteen groups $(n$ $=39$ ) consisted solely of homogeneous thinking styles. All divided groups performed same creative task. The empirical results supported the hypothesis that group formation of diverse thinking style shows better group creativity.
\end{abstract}

Keywords: Group Creativity; Thinking Style; Socio-Cultural Context

\section{Introduction}

Creativity within groups plays an important role in modern society. Creativity is acknowledged as a crucial aspect of doing business, research \& development, arts and many other social domains. Paulus (2000) suggested that interaction in groups can be an important source of creative ideas and innovations. The products of creativity are main factors in the survival of an organization. In addition, in this highly specialized age, the collaboration of each group members is becoming important components of work. Generally, creativity is the ability to produce work that is both novel (i.e., original, unexpected) and appropriate (i.e., useful, adaptive when it comes to task constraints) (Sternberg \& Lubart, 1999). However, creative innovations occur within a socio-cultural context rather than at an individual level. Watson and Crick's discovery of the double helix can be a representative historical example. When meeting Crick, Watson (1968, p.31) notes that "Finding someone... who knew that DNA was more important than proteins was real luck." Thus, we need to empirically evaluate the creative potential (Paulus, 2000) of groups and identify the conditions under which high levels of creativity are realized by groups.

Woo, Lee \& Kim (2009) suggested that cooperative learning depends on not only group members' capability but also quantity and quality of interaction. Therefore, appropriate team composition strategies are necessary to enhance creativity within the group.

Many researchers have a tentative conclusion that heterogeneous group composition is more effective than homogeneous group composition (Sawyer, 2007). Also, group creativity is optimized when group members have different perspectives (Nemeth \& Kwan, 1985). There are reports that discordance between team members thinking increases probability of finding novel and appropriate solutions (Nemeth, Personnaz, Personnaz \& Goncalo, 2004). However, Woo (2010) warned extreme diversity is harmful to group creativity. Based on his finding, Woo (2010) recommend that group composition through cognitive diversity is one of the most effective methods. Also, Kim (2007) suggested that different working styles maximize synergy among group members.

In conclusion, heterogeneous group composition creates a complementary relationship among group members so that group creativity is maximized. However, agreed specific strategies are still absent. Through empirical data this paper aims to discover specific strategies that lead to a significant improvement in students' group creativity. We are considering students thinking styles as the parameter of group creativity, and the affect of thinking styles during learning are also discussed in this study.

\section{Cooperative Learning}

Cooperative learning is a teaching and learning method that aims to achieve a common goal through collaboration with group members (Johnson \& Johnson, 1999). Cooperative learning is an effective teaching method for students to acquire problem-solving skills, critical thinking skills and creativity instead of fragmentary knowledge acquisition. Furthermore, Cooperative learning helps students to develop affective domain such as self-esteem, attitude and social-skills (Johnson, Johnson \& Stanne, 2000). The advantage of cooperative learning coincides with contemporary educational goal.

Jeong, Park \& Hwang (2008) noted that there are lack of studies related to the effective team grouping method although teachers in Korea recognize the necessity of cooperative learning. This is because there is lack of knowledge among teachers in applying the effective model as well aslack of empirical research.

When deducting scientific theories, scientists need active collaboration and lively controversy. In the same vein, students need close collaboration with group members when they learn 
something. However, free-ride effect can occur when solving problems with group members. Effective group composition strategies need to be studied to enhance interdependence among team members (Johnson \& Johnson, 1975).

\section{Thinking Styles}

Thinking styles are the kind of disposition in which people organize or ponder their responses and attitudes toward certain events or work. In other words, thinking styles are the way by which people choose their thought; it does not refer to their capability such as intelligence. It is an issue of whether people want to respond or how they respond to an event.

Sternberg expanded the concept of thinking styles upon mental self-government theory; He used this theory to explain the thinking characteristics of creators. He divided thinking styles into 5 main categories and 13 detailed types (Sternberg, 1988; 1990; 1997). Table 1 shows main categories and detailed types of thinking styles.

The functions of mental self-government are the tangible mental and intellectual reflections of human beings. Generally, a government has three functions: legislative, executive and judicial. Individual's thinking styles can also be divided into three analogous types (Jong, Lin, Wu \& Chan, 2006)

- Legislative: This is the inclination to construct one's own action style and rules as well as the ability to handle unexpected problems on one's own, for example, composing articles, conducting academic research, and creating artistic work. People of this type are typically good at expressing their creativity.

- Executive: This is the inclination to follow rules, deal with expected problems, and practice duties under existing rules. Examples include applying formula to solve problems, giving a speech or teaching based on manuscripts or outlines. People of this type tend to accept commands and act as requested.

- Judicial: This is the inclination to assess regulations and programs, make regulations, handle analyzable materials or conceptual issues. Examples include giving comments, conducting system analysis, and examining plans. People of this type have strong critical analysis skills.

Sternberg thought that thinking styles constitute mental selfgovernment. He indicated that the mental operations of human beings are identical to those of governments by using government organization as a metaphor. Just as a government have department

Table 1.

5 main categories and 13 detailed categories of thinking styles.

\begin{tabular}{lll}
\hline \multicolumn{1}{c}{ Main categories } & \multicolumn{2}{c}{ Detailed types } \\
\hline \multirow{2}{*}{ Functions of mental self-government } & 1. & Executive \\
& 2. & Legislative \\
Forms of mental self-government & 3. & Judicial \\
& 1. & Monarchic \\
Levels of mental self-government & 2. & Hierarchic \\
Orientations of mental self-government & 3. & Oligarchic \\
Ideologies of mental self-government & 4. & Anarchic \\
& 1. & Global \\
& 2. & Local \\
& 2. & External \\
\end{tabular}

to handle events; the same applies to people with different thinking styles.

The three thinking styles mentioned above coexist in each person, but with different levels of portion. Sternberg concluded that a group of people with different thinking styles might perform better in cooperative activities (Sternberg, 1997). Thus, this study investigated the effects of thinking style based group composition on group creativity for students.

\section{Group Creativity}

The early stages of creativity research focused on the psychological determinants for the individual of genius and giftedness (Jeffrey \& Craft, 2001). But research into creativity in the 1980s and 1990s became rooted in social structures effect on individual creativity (Jeffrey \& Craft, 2001). This is socalled social psychology and systems theory. In this context, Sawyer (2003) defined group creativity as 'two or more people do something together pursuing a novel and appropriate outcome. Also, he insisted that group creativity is not fully understood by psychology investigating individuals' inner side. Siau (1995) illustrated components of group creativity as input, process, output (see Figure 1.) Based on the framework of group creativity, Figure 1, group creativity test was developed by Woo (2010).

\section{Method}

\section{Experimental Design}

In this study, pretest-posttest control group (groups of different thinking style members/groups of same thinking style members) design was used and the task of creating a game was given to each group. Before beginning the class, a thinking style test was carried out to divide participant into a control group and an experimental group. After completing the class teaching, a group creativity test was given to the participants. Table 2 shows the design of this study.

\section{Participants}

Seventy three $4 \sim 6^{\text {th }}$ grade students who joined the university summer gifted camp participated in this study. 33 (22 boys, 11 girls) students were assigned as experimental group, and 39 (24 boys, 15 girls) were assigned to control group. The mean age of experimental group was 11.97 years old; the standard deviation was 0.97 , the mean age of control group was 11.97 years old;

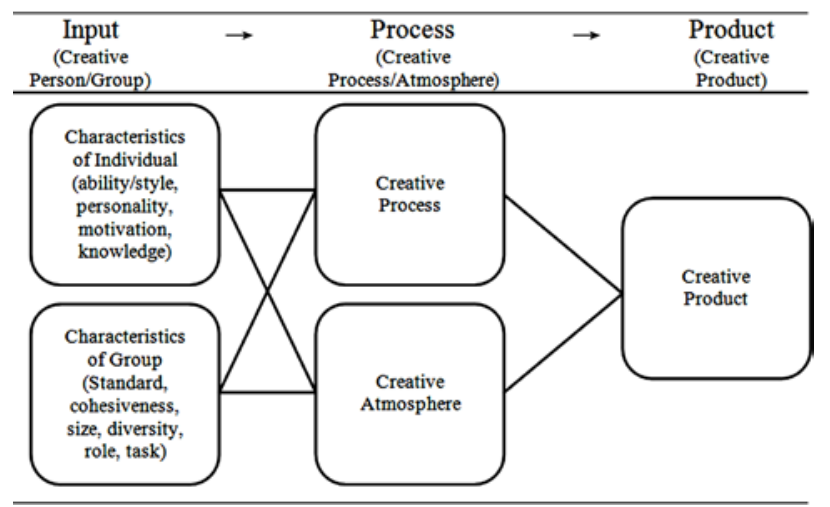

Figure 1.

Components of group creativity (Siau, 1995). 
Table 2.

Pretest-posttest control group design $\left(\mathrm{G}_{1}\right.$ : Experimental group, $\mathrm{G}_{2}$ : Control group, $\mathrm{O}_{1} / \mathrm{O}_{3}$ : Pretest-thinking style questionnaire, $\mathrm{O}_{2} / \mathrm{O}_{4}$ : Posttest-group creativity assessment, $\mathrm{X}_{1} / \mathrm{X}_{2}$ : creative game making task).

\begin{tabular}{cccc}
\hline $\mathrm{G}_{1}$ & $\mathrm{O}_{1}$ & $\mathrm{X}_{1}$ & $\mathrm{O}_{2}$ \\
\hline $\mathrm{G}_{2}$ & $\mathrm{O}_{3}$ & $\mathrm{X}_{2}$ & $\mathrm{O}_{4}$ \\
\hline
\end{tabular}

the standard deviation was 0.49 . All the groups were mixed gender. Levels of inter member familiarity were moderate and homogeneous among and within groups; this was confirmed by the conditions of the summer gifted camp.

\section{Overview of Evaluating Tools}

- Thinking Styles Questionnaire: Sternberg \& Wagner developed Thinking Styles Questionnaire Short Version with 65 questions. Cho (2008) developed Korean version of Thinking Style Questionnaire based on Sternberg \& Wagner's questionnaire (2008), composed of legislative, executive, judicial, hierarchic, global, local, liberal, conservative components with 39 questions. We used Cho (2008)'s Korean Version of Thinking Style Questionnaire to divide groups into heterogeneous thinking style groups and homogeneous thinking style groups.

- Group Creativity Assessment: Woo (2010) developed group creativity assessment tool composed of creative atmosphere, cohesiveness, leadership components. We used Woo (2010)'s group creativity assessment tool to identify the effect of thinking style based group composition.

\section{Procedure}

The experiment consisted of four sessions: a) pre-session survey by questionnaire, b) lecture of making games c) task assignment of creative game making to group members, and d) post-session survey by questionnaire.

First of all, thinking style questionnaire was used to assess the type of individual's thinking style within a 7-point scale, and takes 10 minutes to respond. After finishing pre-session survey, each participant was grouped as a particular three-person group. The same teacher gave a lecture about how to make games with Scratch programming language for approximately 50 minutes.

After that, the teacher asked the participants to create games based on their learning as group working. 90 minutes was allocated for finishing the task. The instruction consisted of following activities: a) producing as many ideas as possible about games, b) not directly adapting ideas that had already existed. After finishing the group task, assessment of group creativity was carried out using 4-point scale questionnaires.

\section{Result}

\section{The Result of Thinking Style Questionnaire}

The data on individual-level of thinking style was aggregated, and the authors examined each questionnaire to assess which thinking style the participants displayed. It is not simply said that one thinking style is the only one for each participant, but we assigned individuals thinking styles based on the one that dominated. We assigned three participants into one group, and the main standard was functions of mental self-government. Table 3 shows the result of group composition.
In the control group, approximately $54 \%$ of groups are the legislative thinking style group. Sternberg \& Grigorenko (1993)'s survey about gifted students' thinking styles demonstrated that gifted students prefer legislative, liberal, judicial thinking styles. Our result was consistent with Sternberg \& Grigorenko (1993)'s research finding.

Then, we used independent group t-test to identify if the group had some difference in thinking style. Table $\mathbf{4}$ shows the result. According to Table 4, there was no significant difference between experimental group and control group of thinking styles $(\mathrm{p}>.05)$.

Table 3.

The result of group composition by thinking style (E: executive, L: legislative, J: Judicial).

\begin{tabular}{cccc}
\hline \multicolumn{2}{c}{ Experimental group } & \multicolumn{2}{c}{ Control group } \\
\hline Group 1 & E, L, J & Group 1 & J, J, J \\
Group 2 & E, L, J & Group 2 & L, L, L \\
Group 3 & E, L, J & Group 3 & L, L, L \\
Group 4 & E, L, J & Group 4 & L, L. L \\
Group 5 & E, L, J & Group 5 & E, E, E \\
Group 6 & E, L, J & Group 6 & J, J, J \\
Group 7 & E, L, J & Group 7 & E, E, E \\
Group 8 & E, L, J & Group 8 & L, L, L \\
Group 9 & E, L, J & Group 9 & L, L, L \\
Group 10 & E, L, J & Group 10 & E, E, E \\
Group 11 & E, L, J & Group 11 & J, J, J \\
- & - & Group 12 & L, L, L \\
- & - & Group 13 & L, L, L \\
\hline
\end{tabular}

Table 4.

The result of independent group t-test of thinking styles between experimental group and control group.

\begin{tabular}{|c|c|c|c|c|c|c|}
\hline & Group & $\mathrm{N}$ & $M$ & $S D$ & $t$ & $p$ \\
\hline \multirow{2}{*}{ Legislative } & Experimental & 33 & 5.01 & 1.19 & \multirow{2}{*}{1.124} & \multirow{2}{*}{.265} \\
\hline & Control & 39 & 4.71 & 1.19 & & \\
\hline \multirow{2}{*}{ Executive } & Experimental & 33 & 4.60 & 1.16 & \multirow{2}{*}{1.411} & \multirow{2}{*}{.163} \\
\hline & Control & 39 & 4.24 & 0.97 & & \\
\hline \multirow{2}{*}{ Judicial } & Experimental & 33 & 4.61 & 1.38 & \multirow{2}{*}{1.368} & \multirow{2}{*}{.187} \\
\hline & Control & 39 & 4.24 & 0.95 & & \\
\hline \multirow{2}{*}{ Hierarchic } & Experimental & 33 & 4.89 & 1.16 & \multirow{2}{*}{1.674} & \multirow{2}{*}{.099} \\
\hline & Control & 39 & 4.43 & 1.17 & & \\
\hline \multirow{2}{*}{ Global } & Experimental & 33 & 4.62 & 1.02 & \multirow{2}{*}{1.474} & \multirow{2}{*}{.145} \\
\hline & Control & 39 & 4.26 & 1.03 & & \\
\hline \multirow{2}{*}{ Local } & Experimental & 33 & 4.56 & 1.08 & \multirow{2}{*}{1.659} & \multirow{2}{*}{.102} \\
\hline & Control & 39 & 4.16 & 0.98 & & \\
\hline \multirow{2}{*}{ Liberal } & Experimental & 33 & 4.85 & 1.32 & \multirow{2}{*}{.867} & \multirow{2}{*}{.389} \\
\hline & Control & 39 & 4.57 & 1.41 & & \\
\hline \multirow{2}{*}{ Conservative } & Experimental & 33 & 4.33 & 1.06 & \multirow{2}{*}{1.782} & \multirow{2}{*}{.079} \\
\hline & Control & 39 & 3.92 & 0.89 & & \\
\hline
\end{tabular}




\section{The Result of Group Creativity Assessment}

In this study, we regarded group-level of creativity as determined by aggregation of group creativity assessment tool developed by Woo (2010). More precisely, we used the following procedure in constructing each index of group creativity. a) Calculate the mean score of each of the components of group creativity such as Creative atmosphere, Cohesiveness, and Leadership. Especially, creative atmosphere is consisted of sub-components such as support, trust, pleasure, challenge and communication. b) Calculate the mean of total component. Independent group t-test revealed significant difference in support, pleasure and leadership $(\mathrm{p}<.05)$ (see Table 5).

The result indicates that groups achieved the best performance when they had high degrees of diversity in thinking styles. Especially, high levels of diversity within thinking styles are effective in creating a supportive atmosphere, drawing interests and demonstrating leadership.

\section{The Qualitative Data from Class Observation}

We also recorded class with video camera to analyze interaction between group members. Generally, experimental group had active interaction from beginning to end. In control group, composed of judicial only, had the lowest interaction. In addition, one interesting phenomenon was observed in groups of legislative only groups. These groups showed very active interaction at the beginning of task, especially in idea generation.
Every team member in legislative only groups was busy thinking of new games. However, the active interaction disappeared as time went on. After idea generation, they had to give shape to a plan and implement the idea to make a creative game. But, they had difficulty in implementing ideas. Even some groups could not finish the task.

The results indicate that diverse thinking style group members complement their shortcomings each other so that it helps finishing the task. The result suggests that a form of synergy between diverse thinking style group members operates in group creativity.

\section{Discussion}

In this study, we intended to investigate the prediction that diversity in thinking styles of group members is a prerequisite to obtaining benefits from different thinking styles when the group engages in a creative activity.

As the research hypothesis that groups with high levels of diversity in thinking styles within group members may gain greater benefits from group working than homogeneous group working, the experiment supported the hypothesis. From this result, diversity in thinking styles showed a form of synergy between group members that is effective in group creativity. Furthermore, groups formed with different thinking style members showed higher levels of collaboration than that of homogeneous thinking styles groups.

Table 5.

The result of independent group t-test of group creativity between experimental group and control group.

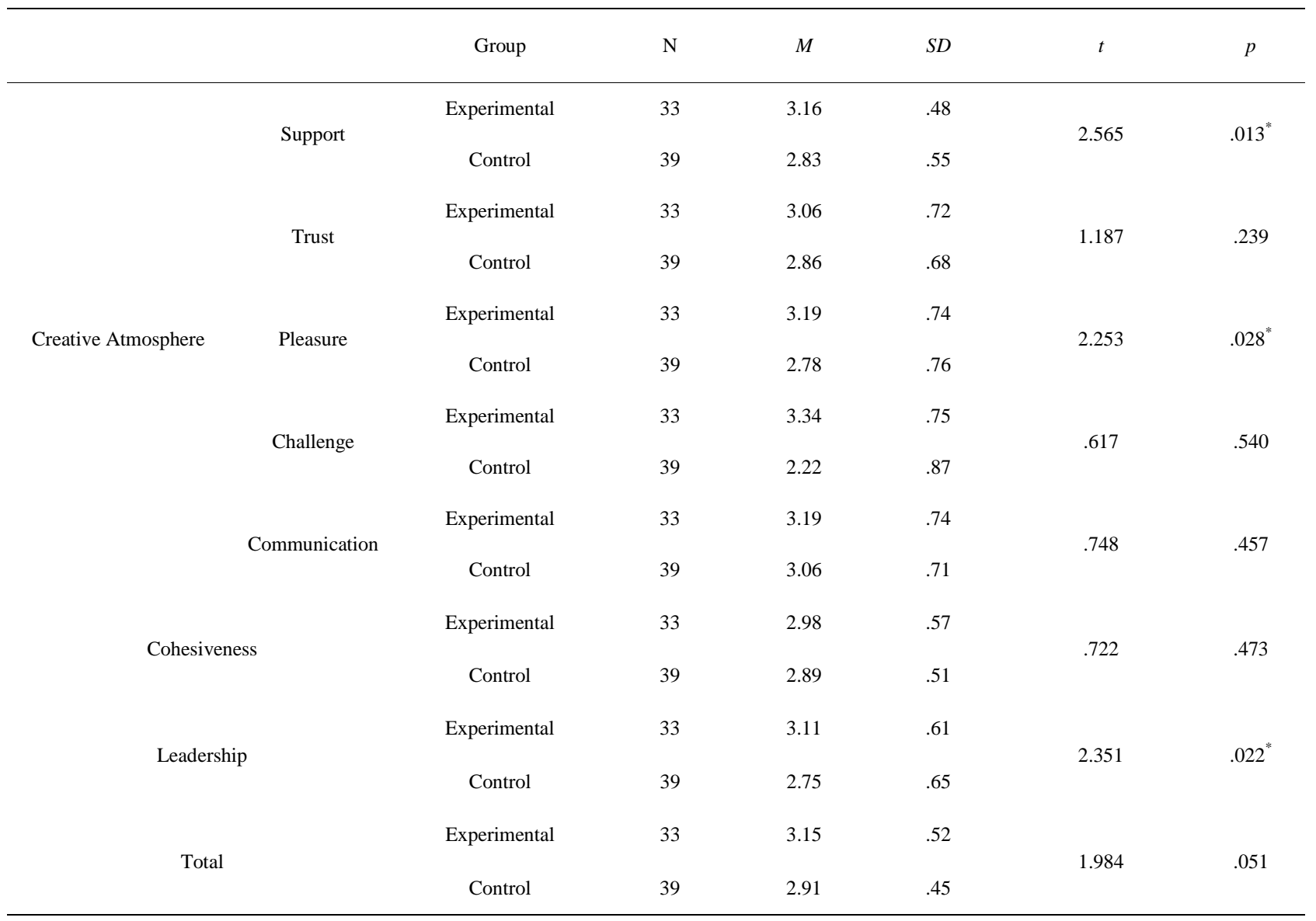


It is interesting that this hypothesis is working at the elementary and middle school level classroom teaching. This implies that the group formation strategies affect overall classroom productivity but needs further studies due to the importance of the K-12 education period of acquiring characters to tolerate and cooperation with others.

\section{Acknowledgements}

This work has been supported by the Korea National University of Education Fund in 2012.

\section{REFERENCES}

Cho, K.T. (2008). Relations with Sternberg's thinking styles, learning styles and problem solving. Ph.D. Thesis. Chung-Ang University.

Jeffrey, B. \& Craft, A. (2001). The universalization of creativity. In A. Craft, B. Jeffrey, \& M. Leibling (Eds.). Creativity in education. London: Continuum International Publishing Group.

Jeong, H.C, Park, Y.S \& Hwang, D.J (2008) Analyzing perceptions of small group inquiry activity in the gifted education of Korea. Journal of the Korean earth science society, 29(2), 151-162

Johnson, D.W. \& Johnson, R.T. (1975) Learning together and alone: cooperation, competition and individualization. Englewood Cliffs. NJ: Prentice Hall.

Johnson, D.W. \& Johnson, R.T. (1999) Learning and together and alone: Cooperative, competitive and individualistic learning $\left(5^{\text {th }}\right.$ ed.). Boston: Allyn and Bacon.

Johnson, D.W., Johnson, R.T. \& Stanne, M.B. (2000). Cooperative learning methods: A meta-analysis. Retrieved january 20th, 2011 from http:// www.tablelearning.com/uploads/File/EXHIBIT-B.pdf

Jong, B.S., Lin,T.W., Wu,Y.L., \& Chan,T.Y. (2006). Effective two phase cooperative learning on the WEB. Journal of Information Science and Engineering, 22(2), 425-446.

Kim, Y.C (2007) Group creativity: How it could be effective? The Korean Journal of Thinking \& Problem solving, 3(1), 1-26.

Nemeth, C. \& Kwan, J.L. (1985) Learning together and alone: cooperation, competition and individualization. Englewood Cliffs, NJ: Prentice Hall.

Nemeth, C., Personnaz, M., Personnaz, B., \& Goncalo, J. (2004) The liberating role of conflict in group creativity: A cross-cultural study. European Journal of Social Psychology, 34, 365-374.

Paulus, P.B. (2000) Groups, teams, and creativity: The creative potential of idea-generating groups. Applied Psychology: An International Review, 49, 237-262.

Sawyer, R.K. (2007) Group creativity: Music, theater, collaboration. Mahwah, NJ: Lawence Eribaum.

Sawyer. R. K. (2007). Group genius: The creative power of collaboration. New York: Basic Books. Sawyer, R. K. (Editor). (2006). Cambridge handbook of the learning sciences. New York: Cambridge University Press.

Siau, K. L. (1995). Group Creativity and Technology. Journal of Creative Behavior, 29(3). 201-216.

Sternberg, R. J. (1988). Mental Self-government: A theory of intellectual styles and their development. Human Development, 31, 197-224.

Sternberg, R. J. (1990). Thinking Styles: Keys to understanding student performance. Phi Delta Kappan, 71, 366-371.

Sternberg, R. J. (1997). Thinking Styles. New York: Cambridge University Press.

Sternberg, R. J., \& Wagner, R. K. (1992). Thinking styles inventory. New Haven, Yale University, Unpublished Inventory.

Sternberg, R.J. \& Grigorenko, E.L. (1995) Thinking style and gifted. Roeper Review, 16(2), 122-130.

Watson, J.D. (1968) The double helix: A personal account of the discovery of the structure of DNA. New York: New American Library.

Woo, S.H, Lee, H.J \& Kim, J.W (2009) A method of composing an effictive design cooperative learning group-elementary school students in the early grades, Journal of Korean society of design science, 22(4). 93-108.

Woo, S.H. (2010) Design cooperative learning for promoting creativity on early elementary grades: A method for group composition. Ph.D. Thesis, Yeon-sae university. 